\title{
A STUDY ON CORRELATION OF SIZE AND SITE OF TYMPANIC MEMBRANE PERFORATION WITH DEGREE OF CONDUCTIVE HEARING LOSS IN CHRONIC OTITIS MEDIA
}

\author{
Authors: Lavanya $\mathrm{M}^{1}$, Srinivas $\mathrm{V}^{2}$ \\ (1) Senior Resident, (2) Professor\&H.O.D, \\ Department of ENT, BGS Global Institute of Medical Sciences, Bangalore, Karnataka. \\ Address of corresponding author \\ DrSrinivas V \\ Professor and HOD, Department of ENT \\ BGS Global Institute of Medical Sciences, \\ Bangalore, Karnataka. \\ Email id:lavanyamanjunath06@gmail.com \\ Mobile no: $+91-8904456447$
}

\section{ABSTRACT}

Background: Tympanic membrane perforations are common cause of hearing loss. This study was designed to analyze the relation between tympanic membrane perforation and conductive hearing loss.

Materials and Methods: In this prospective study, patients with dry tympanic membrane perforations of safe type were included. The patients were divided into groups in according to size, site and duration of perforation. Based on the inclusion and exclusion criteria a total of 100 patients were included in this study. All the patients clinical data was analyzed statistically using paired t-test.

Results: Hearing loss increased as the size of perforation increased. Posterior quadrant perforations were associated with more hearing loss as compared to anterior quadrant perforations. Also duration of disease was in linear relation with mean hearingloss.

Conclusions: The degree of conductive hearing loss as a result of tympanic membrane perforation would be expected with the size, site and duration of perforation.

Keywords: Tympanic membrane, Conductive hearing loss, Perforation, hearing loss, posterior quadrant, ear.

Introduction
Tympanic membrane separates middle ear from the external ear, measuring 9-10 mm vertically and 8$9 \mathrm{~mm}$ horizontally. It transmits sound in middle ear'. Apart from conduction of sound waves across the middle ear, the tympanic membrane, also sub-serves a protective function to the middle ear cleft and round window niche ${ }^{2}$. Chronic otitis media (COM) has been defined as a longstanding inflammatory condition of the middle ear and mastoid associated with or without a perforation of the tympanic membrane. COM with a perforation often is accompanied by a past and present history of intermittent otorrhea and conductive hearing loss.Chronic Suppurative Otitis Media(CSOM) is a wide spread disease of the developing countrieslike India especially in the rural areas ${ }^{4,5}$. It is one of the commonest causes of hearing loss that mainly results due to a tympanic membrane perforation. The large effective surface area of an intact and normally vibrating tympanic membrane plays a major role in the middle ear transformer mechanism. Perforation of the tympanic membrane is a common cause for hearing loss due to loss of effective area of vibration. Perforations can result from various reasons including middle ear disease, trauma. Tympanic membrane (TM) perforation reduces the total ratio of surface area, allowing the sound waves to directly pass through the middle ear. It is a highly prevalent condition and an important cause of preventable hearing loss $^{6}$. Perforated eardrum results in conductive hearing loss, and this range is reported not to exceed $50 \mathrm{~dB}^{7} 9$. Accurate assessment of the TM Perforation and its relationship with hearing loss is important as it enables the clinician to optimally 
assess the condition and offer an appropriate solution.The objective of this study was to analyze the correlation between tympanic membrane perforation and hearing loss.

\section{Materials and Methods}

\section{Source of data}

Patients attending ENT OPD BGS GIMS in the study period from April 2019 to Jan 2020 who have Tympanic membrane perforation

\section{Study design}

A prospective study design was made and sample size was set at 70 perforated ears in 49 patients and safe CSOM. The patients were divided into 2 to 3 groupsdepending on size of perforation. The site of perforation was recorded and a pure tone audiogram is performed on the patient.

\section{Inclusion criteria}

- Subject should have centralTM perforation due to trauma or CSOM

- All subjects should have dry ears (duration 3 months)

- Patients with intact ossicular chain.

- Age between 15-50yrs.

\section{Exclusion criteria}

- Patients with Atticoantraldisease - presence of cholesteatoma orgranulation tissue.

- ActiveCSOM.

- Patients with Ossicularchain pathology.

- Patients who cannot give a valid and consistent PTA response.

- Patients with sensorineural hearing loss

\section{Data collection}

This study was approved by Institutional Human Ethics Committee (IHEC). A thorough history was taken in each case and patients underwent detailed ENT examination. The type, degree and frequency of hearing loss were determined by PTA (Pure Tone Audiometry). Average AC threshold was calculated at 500, 1000 and $2000 \mathrm{~Hz}$.Depending upon the area of perforation of tympanic membrane, patients were divided into 3 groups.

Group-I:Smallperforation

Group-II:Mediumperforation

Group-III: Largeperforation

Depending upon the site of perforation of tympanic membrane, patients were divided into 3 groups.

Group-A: Anterior (Anteroinferior and anterosuperior quadrant)perforation.

Group-B: Posterior (Posteroinferior andposterosuperior quadrant)perforation.

Group-C: Central (Multiple quadrants)perforation.

Depending upon the duration of disease, patients were divided into 3 groups.

Group-1:<1year

Group-2: 1-5years

Group-3:>5years

The association of degree of hearing loss was matched with the characteristics of perforation and result thus obtained was evaluated.

\section{Statistical analysis}

The data was expressed in number, percentage, mean and standard deviation. Statistical Package for Social Sciences (SPSS 16.0) version used for analysis. Paired $t$ test applied to find the statistical he results of our study were analysed on SPSS Software using paired t test.

\section{Results}

A total of 49 patients with unilateral or bilateral CSOM (total perforated tytmpanic membranes $=70$ ) were included in the study. Maximum patients were in age group of 20 to 30 .In ourstudynumber of males was 29andfemaleswere 21 with Male:Female ratio of 1.38:1. Bilateral CSOM was seen in 21 patients, left CSOM in 19 patients and right CSOM in 9 patients. Otorrhea was the presenting complaint in $100 \%$ patients followed by impaired hearing.On comparing the mean hearing loss of group I, group II and group III, difference was found to be statistically significant $(p<0.001)$. Thus there is significant increase in mean hearing loss from small perforation to medium perforation and most in the large 
perforation (Table-1 and Graph-1).

\begin{tabular}{|l|c|c|c|}
\hline \multicolumn{1}{|c|}{ Groups } & Number & Percentage (\%) & $\begin{array}{c}\text { Hearing loss } \\
(\mathrm{MEAN} \pm \mathrm{SD})\end{array}$ \\
\hline Group-I & 16 & 22.86 & $28.42 \pm 3.44$ \\
\hline Group-II & 31 & 44.28 & $35.16 \pm 3.39$ \\
\hline Group-III & 23 & 32.86 & $40.40 \pm 4.96$ \\
\hline
\end{tabular}

Graph-1: Comparison of mean hearing loss between the groups

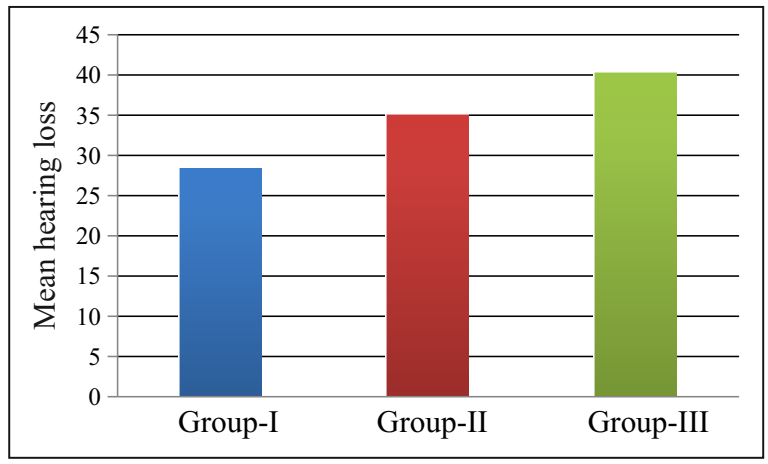

On comparing the mean hearing loss of group $A$, group $B$ and group $C$, difference was found to be statistically significant with $p<0.001$. Thus we concluded that there is significant increase in mean hearing loss from anterior perforation to posterior perforation (Table-2 and Graph-2).

Table-2: Distribution of patients based on the site of perforation

\begin{tabular}{|l|c|c|c|}
\hline Groups & Number & Percentage (\%) & $\begin{array}{c}\text { Site of } \\
\text { perforation } \\
\text { (MEAN } \pm \text { SD) }\end{array}$ \\
\hline Group-A & 11 & 15.71 & $27.11 \pm 3.12$ \\
\hline Group-B & 16 & 22.86 & $36.96 \pm 2.79$ \\
\hline Group-C & 43 & 61.43 & $42.40 \pm 4.34$ \\
\hline
\end{tabular}

Graph-2: Comparison of mean site of perforation between the groups

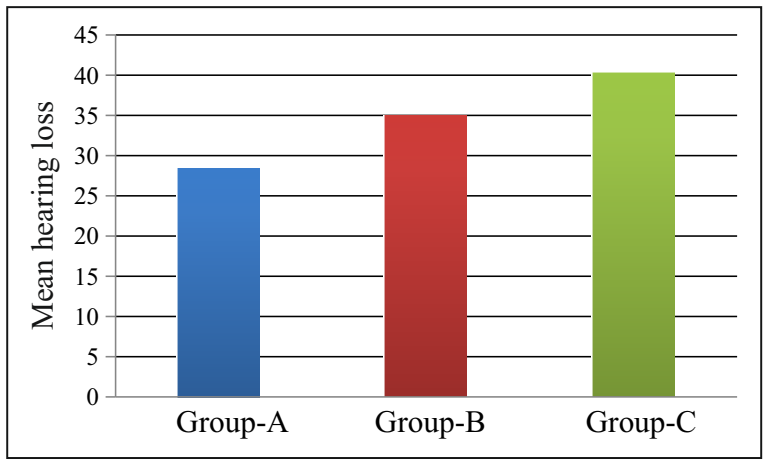

From the above result, we observed that mean hearing loss increased significantly as the duration of disease increased (Table-3 and Graph-3).
Table-3: Distribution of patients based on the duration of perforation

\begin{tabular}{|c|c|c|c|}
\hline Groups & Number & Percentage (\%) & $\begin{array}{c}\text { Duration of } \\
\text { perforation } \\
\text { (MEAN } \pm \text { SD) }\end{array}$ \\
\hline Group-1 & 18 & 25.71 & $25.89 \pm 6.20$ \\
\hline Group-2 & 32 & 45.71 & $30.91 \pm 8.12$ \\
\hline Group-3 & 20 & 28.58 & $36.49 \pm 11.10$ \\
\hline
\end{tabular}

\section{Graph-3: Comparison of mean duration of perforation between the groups}

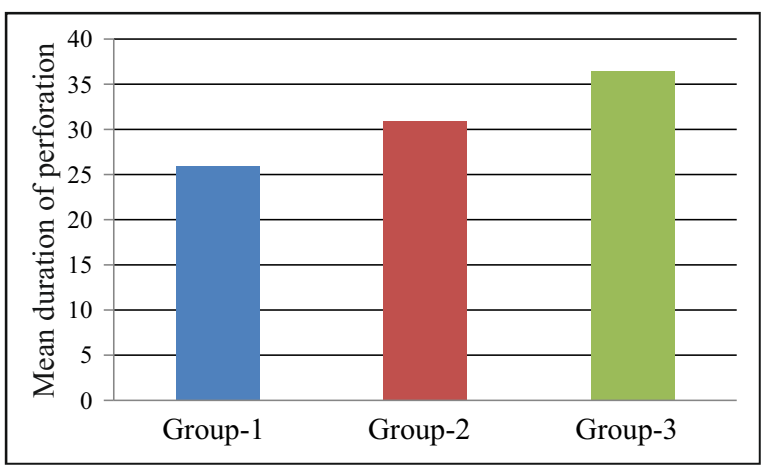

\section{Discussion}

The study included 49 patients, 21 patients had involvement of both ears so total number of ears involved in this study were70.In this study, most common affected age group was $20-30$ years. The possible reason could be that this group is socially more active and is more health conscious. This finding is in accordance with Deepak et al and Prasansuk et al..$^{10,11}$ The number of males in the study group was higher than the number of females $(M: F=1.38: 1)$. Rafique et al in their study found $M: F$ ratio of 1.25:1. Kurian also reported higher incidence of disease in males. The most common symptom was ear discharge (on and off) from the diseased ear which is consistent with study of Kumar et al 13,14. The size of perforationcomparing the degree of hearing loss with various size of perforation, it was observed that hearing loss increased with increased size of perforation. Our result was comparable with Vijayshree et al, Kumar et al and Pannu et al. ${ }^{6,14,15}$ Baumann et al also reported a linear relation between the size of perforation and amount of hearing loss. ${ }^{16}$

Site of perforation in this study posterior quadrant perforations have higher mean hearing loss than anteriorly located perforations with statistically significant $p$ value. However, hearing loss was highest in perforations involving multiple quadrants. This view has been supported by Vijayshree et al, Bianca et al and Malik et al. ${ }^{6,17,18}$ This can be attributed to the 
direct exposure of round window to the sound waves resulting in cancellation of phase difference between the oval and round windows. However, Herkat et al, Kumar et al and Pannu et al differed in this view in their study. ${ }^{14,15,19 .}$ In our study, hearing loss increased as the duration of disease increased. On comparing hearing loss in all the three groups, it was observed that average hearing loss increased significantly as the duration of disease increased. Our observation regarding the duration of disease is similar to Pannuet al. ${ }^{15}$

\section{Conclusion}

Tympanic membrane perforation causes hearing loss ranging from mild to moderate. From our study, we concluded that the hearing loss increased with size of perforation and with posterior location of tympanic membrane perforation. A thorough knowledge of all these results would allow us to clinically predict the hearing loss based on size and site of perforation.

\section{Source of funding}

Self-financed

\section{Conflict of interest}

None declared

\section{REFERENCES}

1. Ogisi FO, Adobamen P. Type 1 Tympanoplasty in Benin:A 10-year review. Nigerian Postgraduate Med J.2004;11(2):84-7.

2. Voss SE, Rosowski JJ, Merchant SN, Peake WT. Non-ossicular signal transmission in human middle ears: Experimental assessment of the "acoustic route" with perforated tympanic m e m branes. J A c o u s t S o c Am.2007;122(4):2135-53.

3. FischU, May JS, Linder T. Tympanoplasty, Mastoidectomy and Stapes Surgery. 2nd ed. Ann R CollSurg Engl. 2010;92(1):81.

4. B o oth J B. Manage me $n t$ of chronicsuppurativeotitis media. Scott-Brown's Otology.1997;3:10-1.

5. Shrestha R, Baral K, Neil W. Community ear care delivery by community ear assistants and volunteers: a pilot study. J LaryngolOtol. 2001;115(11):869-73.
6. Nahata V, Patil CY, Patil RK, Gattani G, Disawal A, Roy A. Tympanic membrane perforation:Its correlation with hearing loss and frequencyaffected-An analytical study. Indian J Otol.2014:20(1):10-5.

7. Voss SE, Rosowski JJ, Merchant SN, Peake WT. How do tympanic-membrane perforations affect human middle-ear sound transmission? ActaOtolaryngol.2001;121(2):169-73.

8. Voss SE, Rosowski JJ, Merchant SN, Peake WT. Middle-ear function with tympanic-membrane perforations. II. A simple model. J AcoustSoc Am. 2001;110(3):1445-52.

9. Voss SE, Rosowski JJ, Merchant SN, Peake WT. Middle-ear function with tympanic-membrane perforations. I. Measurements and $\mathrm{mech}$ a n i s m s. J A cous t Soc Am.2001;110(3):1432-44.

10. Dessai TD, Philip R. Influence of Tympanic Membrane Perforation on Hearing Loss. Glob J Oto. 2017;5(5):55-73.

11. Prasansuk S, Hinchcliffe R Tympanic membrane perforation discriptors and hearing levels in otitis media. Audiology.1982;1:43-51.

12. Rafique M, Farrukh MS, Shaikh AA. Assessment of Hearing Loss in Tympanic Membrane Perforation at Tertiary Care Hospitals. JLUMHS.2014;13(1):32-6.

13. Kurian CA, Reghunandanan SG, Viswanathan K, Mohammad lqbal MK, Ravi A. Homologous dura for myringoplasty. Indian J Otolaryngol Head Neck Surg.1996;48(2):150-2.

14. Kumar N, Chilke D, Puttewar MP. Clinical Profile of Tubotympanic CSOM and Its Management With Special Reference to Site and Size of Tympanic Membrane Perforation, Eustachian Tube Function and Three Flap Tympanoplasty. Indian J Otolaryngol Head Neck Surg.2012;64:512.

15. Pannu KK, Chadha S, Kumar D, Preeti. Evaluation of hearing loss in tympanic membrane 
perforation. Indian J Otolaryngol Head Neck Surg. 2011;63:208- 13.Baumann I, Gerendas B, Plinkert PK, Praetorius M. General and disease specific quality of life in patients with chronic suppurative otitis media-a prospective study. Health Qual Life Outcomes. 2011;29(9):48.

16. Bianca N, Doina V, Ermil T. Annals of the University of Lower Danube Galati. Medicine BeamXVII. 2011;2:17.

17. Malik S, Ashrafi K, Sohail Z, Afaq S, Nawaz A. Determinants of variable hearing loss in patients with chronic suppurative otitis media. Pak J Otolaryngol.2012;28:45-7.

18. Herkal K, Ramasamy K, Saxena SK, Ganesan S, AlexanderA.Hearing loss in tympanic membrane perforations:an analytic study. Int J OtorhinolaryngolHead Neck Surg. 2018;4(5):1233-9. 